\title{
Cost-effectiveness of vildagliptin for people with Type 2 Diabetes Mellitus in Brazil; findings and implications
}

Gustavo Laine Araujo de Oliveira ${ }^{1}$, Augusto Afonso Guerra Junior ${ }^{1,2}$, ${ }^{*}$ Brian $_{\text {Godman }}^{3,4}$, Francisco de Assis Acurcio ${ }^{1,2,5}$

${ }^{1}$ Department of Social Pharmacy, School of Pharmacy, Federal University of Minas Gerais, Belo Horizonte, Brazil. Email: gustavolaine@gmail.com; augustoguerramg@gmail.com; acurcio@ufmg.br

${ }^{2}$ SUS Collaborating Centre - Technology Assessment \& Excellence in Health, College of Pharmacy, Federal University of Minas Gerais, Minas Gerais, Brazil

${ }^{3}$ Strathclyde Institute of Pharmacy and Biomedical Sciences, University of Strathclyde, Glasgow, UK. Email: Brian.godman@strath.ac.uk

${ }^{4}$ Department of Laboratory Medicine, Division of Clinical Pharmacology, Karolinska

Institutet, Karolinska University Hospital Huddinge, Stockholm, Sweden. Email:

Brian.Godman@ki.se

${ }^{5}$ School of Medicine, Federal University of Minas Gerais, Belo Horizonte, Brazil

*Correspondence author: Brian Godman, Strathclyde Institute of Pharmacy and Biomedical Sciences, University of Strathclyde, Glasgow G4 0RE, United Kingdom. Email:

Brian.godman@strath.ac.uk. Telephone: 0141548 3825. Fax: 01415522562 and Department of Laboratory Medicine, Division of Clinical Pharmacology, Karolinska Institutet, Karolinska University Hospital Huddinge, SE-141 86, Stockholm, Sweden. Email: Brian.Godman@ki.se. Telephone: 00468585 81068; Fax: 0046858581070

\begin{abstract}
Introduction: Vildagliptin is an inhibitor of the enzyme dipeptidyl peptidase 4, indicated for the treatment of type 2 diabetes mellitus, combined or not with metformin. This study aims to evaluate the cost-effectiveness of vildagliptin in the Brazilian context. Areas covered: Using MEDLINE, Cochrane Library, Lilacs and CRD, six studies were selected for the economic models. This study utilised cost data in the Brazilian health system to provide the context. Expert commentary: Type 2 diabetes mellitus is an epidemic disease and represents a challenge for all health care systems. Although guidelines clearly define first-line treatment, there are several other promising treatments. Vildagliptin is one of them, resulting in a mean lifetime increase of 0.31 years compared to metformin alone and 1.19 more life years compared to other metformin combinations. Considering observational data, life years with dual vildagliptin-containing treatments were 0.37 more compared to other dual treatments. However, its high cost versus generic metformin and its unclear safety profile weakens its subsequent cost-effectiveness. Consequently, the incorporation of vildagliptin or its combination with metformin is currently not recommended for the Brazilian Health Care System. This may change as more data becomes available.
\end{abstract}

Key words: vildagliptin, cost-effectiveness, Brazil, Type 2 diabetes, metformin

\section{Introduction}

Diabetes mellitus is a major public health problem. In 2014, it was estimated there were 422 million people worldwide with the disease, $8.5 \%$ of the adult population [1], although others estimated 415 million in 2015. In any event, the prevalence is envisaged to increase to 642 
million by 2040 [2]. Globally, diabetes alone was estimated to kill 4.6 million people in 2013 [3]. Type 2 diabetes mellitus (T2DM) is the most prevalent of the type, affecting between $90 \%$ and $95 \%$ of patients with diabetes. Annual treatment expenditures of people living with diabetes is currently estimated at US $\$ 827$ billion, representing $12 \%$ of the total worldwide expenditure on health. Approximately half of adults affected by diabetes are currently undiagnosed, and it is estimated that one person dies from this disease every six seconds $[1,2]$.

There are many medicines available for treatment of patients with T2DM. Among these, there are insulin preparations including insulin analogues as well as oral and injectable and hypoglycemic agents. In the essential medicines lists of Brazil, there are regular and NPH insulins, in addition to oral hypoglycemic agents metformin, glibenclamide and gliclazide [4]. This alongside encouraging lifestyle changes including diet and exercise.

Antihypertensives, including renin-angiotensin inhibitors, statins and anti-platelet medicines are also prescribed concomitantly with hypoglycaemic medicines and insulin to reduce the complications of patients with T2DM, which include cardiovascular complications and nephropathy [5-7]. Metformin is usually prescribed as first line therapy in patients with T2DM given its beneficial effects on HbA1c, weight, and cardiovascular mortality as well as its relative safety profile [8-12]. In addition, it has a very low cost compared with newer treatments. The place of second line medicines in combination with metformin is now becoming clearer following recent studies and meta-analyses. For instance in a recent cohort study conducted in the UK, dual treatment with dipeptidyl peptidase-4 inhibitors, also called gliptins, and metformin was associated with a decreased risk in heart failure (38\%), cardiovascular disease (33\%) and mortality (48\%). Triple treatment with metformin, sulphonylureas, and gliptins was also associated with a decreased risk of key outcomes, e.g. $40 \%$ reduction for heart failure, $30 \%$ for cardiovascular disease, and $51 \%$ for all cause mortality [10]. Reductions in cardiovascular events were also seen in other studies [13]. However, other authors are more cautious about the impact of dual therapy with gliptins reducing cardiovascular risk [14]. Recent reviews have further pointed out that gliptins have a neutral effect on cardiovascular outcomes and stroke [15-18]. A crucial area in the management of patients with T2DM is adherence to medicines, which is typically seen as suboptimal across countries [3,19-21], although studies have suggested greater compliance with metformin and the gliptins versus other combinations [22].

Vildagliptin is a selective dipeptidyl peptidase-4 inhibitor. It acts on the alpha and beta pancreatic cells, preventing incretins degradation. With increased levels of these substances, there is a good response of the islets of Langerhans to help with glycemic control through insulin regulation and glucagon [23]. The potential benefits of vildagliptin include a lower incidence of weight gain, hypoglycemia and peripheral oedema compared with other oral hypoglycaemic medicines [24].

The recent beneficial findings with the gliptins including vildagliptin have resulted in the Brazilian public health system being sued in the courts and requested to provide vildagliptin for patients. This is because of the stated goal of universal access to healthcare for all patients in Brazil, with the potential for citizens to take their case to court if they believe they are not being treated appropriately [25]. According to data from the federal government in 2014 more than 460,000 tablets of vildagliptin were acquired, representing an expenditure of nearly US\$515,000, with vildagliptin the most requested gliptin in lawsuits. [26]. Brazilian states and municipalities also need to fulfil any regional court rulings further increasing sales. This is why vildagliptin was chosen for this study as opposed to other gliptins. 
However, evidence to support the use of vildagliptin in Brazilian context are scarce for both monotherapy and combination therapy. To check the relevance or not of the inclusion of vildagliptin into Brazilian T2DM guidelines, studies are needed to understand the economic impact alongside any clinical benefits. Consequently, we sought to evaluate the costeffectiveness of vildagliptin monotherapy or combined with any oral hypoglycemic agent for people living with T2DM under Brazilian public health system perspective based on available data from clinical trials and observational studies.

\section{Methods}

\subsection{Search strategy}

A systematic search using the MEDLINE, Cochrane Library, LILACS (Latin American and Caribbean Literature in Health Sciences) and CRD (Center for Reviews and Dissemination) databases was conducted in July 2016 to identify published articles assessing the clinical outcomes of vildagliptin for diabetes mellitus Type 2 . The search strategies were constructed with terms related to the disease and the medication.

\subsection{Eligibility criteria}

Two reviewers were involved in assessing the abstracts and disagreements were resolved by consensus. The studies were considered relevant if: (a) they evaluated the treatment of patients with type 2 diabetes mellitus; (b) vildagliptin, combined or not with metformin, was an arm of the study; (c) comprised a follow-up of at least 52 weeks as this is chronic medication with long term outcomes. Following this process, 770 abstracts were identified. Six papers were finally selected for the analysis. Data on efficacy, effectiveness and safety of treatments were extracted. The complications of the disease were classified according to the ICD-10 code, which allows the identification of the associated costs in the databases of the Brazilian health system. The definition of outcomes was considered as reported in the studies. In particular, hypoglycaemia was defined as symptoms suggestive of low blood glucose confirmed by self-monitored blood glucose measurement of $<3.1 \mathrm{mmol} / 1$.

\subsection{Economic models}

A Markov model was designed considering a hypothetical cohort of T2DM patients, divided into groups according to their pharmacotherapy and the type of studies considered. Based on the transition probabilities between a stage of the disease and another, this type of model allows the simulation of the disease's progression in a population according to time cycles. Consequently, each stage of the disease is considered in the model as a transition state [27].

The main objective of treatment is to keep the patient free of T2DM complications. Secondly, $\mathrm{HbA} 1 \mathrm{c}$ levels are expected to remain below $7.0 \%$ to help prevent the complications of T2DM including hospitalisation. In this way, the models were developed to assess the efficiency of different approaches in keeping patients free of clinical conditions that result in either secondary or tertiary care. We did not look further at efficiency based on cost per quality adjusted life years (Cost/ QALYs) as no utility data was available in the Brazilian context. This is research for the future. 
To evaluate the retention capacity of patients at the primary care level, all stages of the disease that require specialized care were considered absorbent states. Absorbent states are those in which the patient does not progress to another state within the built hypothetical cohort.

In this study, each cycle has one-year duration and the model comprises a time horizon of 10 years that starts with the mean age of patients reported in the literature. In the first model cycle, the hypothetical cohort's population is comprised of individuals with T2DM, HbA1c higher than $7.0 \%$ and no complications from the disease. Transition from the first to the second cycle, and successively, takes place according to the probabilities of transition from each state.

Models were composed of transition states, mutually exclusive, which correspond to the possible stages of the disease. Consequently, transitions were considered from T2DM no complications to other states as reported in studies directly comparing vildagliptin with other therapeutic alternatives, combined or not with metformin.

Transition probabilities are developed with data on disease's progression and the efficacy or effectiveness of the medicines in question. The relevant information was obtained from randomized clinical trials and retrospective or prospective observational studies with a minimum follow-up of 52 weeks. Studies with short follow-ups were not used because in this period there is a greatest reduction in $\mathrm{HbA1c}$ and then, its elevation is observed. Studies with a minimum follow-up of 52 weeks best represent sustained levels of HbA1c. Consequently, study selection was made based on this criterion in our models.

Model 1 was built to evaluate the cost-effectiveness of vildagliptin $50 \mathrm{mg}$ b.i.d. monotherapy, compared to metformin $850 \mathrm{mg}$ b.i.d. monotherapy, to avoid the occurrence of hypoglycemic events according Schweizer et al (2007) [28]. In Model 2, the cost-effectiveness of vildagliptin $50 \mathrm{mg}$ b.i.d. and metformin $850 \mathrm{mg}$ b.i.d. in combination was estimated to avoid the occurrence of complications, such as those documented on the clinical trials of Bolli et al (2009) [29], Ferrannini et al (2009) [30] and Filozof (2010) [31]. These studies compared this combination to, respectively, pioglitazone $30 \mathrm{mg}$ per day, glimepiride 2 to $6 \mathrm{mg}$ per day and gliclazide $320 \mathrm{mg}$ per day, all combined with metformin. In Model 3, we considered data from observational studies of Mathieu et al (2013) [32] and Montilla et al (2014) [33] to estimate the cost-effectiveness of vildagliptin-containing treatments compared to regimens in which do not have this medicine. Mathieu et al (2013) reported the comparative effectiveness of metformin combined with vildagliptin or to any other oral hypoglycemic agent. In the study of Montilla et al (2014), the populations were divided by those that used vildagliptin and those that had not used vildagliptin, combined or not with any other oral hypoglycemic agent. There was no dose setting in these two studies.

In Model 1, the transition states were the discontinuation of the treatment due to adverse events, HbAlc higher than 7.0\%, hypoglycemia and death. Model 2 considered the same states of Model 1 with the addition of acute coronary syndrome, congestive heart failure, stroke, transient ischemic attacks and peripheral arterial disease. In Model 3, as this was derived from observational studies, hypoglycemia, renal insufficiency, stroke, pneumonia, pericardial effusion, leukemia, colon adenoma, colon cancer, bladder cancer, breast cancer and death were considered (Table 1). 
Table 1. Annual probabilities and costs for the evaluation of vildagliptin-containing treatments for Type 2 Diabetes Mellitus.

\begin{tabular}{|c|c|c|c|}
\hline \multicolumn{4}{|l|}{ TRANSITION PROBABILITIES } \\
\hline & Value & Distribution & Reference \\
\hline \multicolumn{4}{|l|}{ Model 1 variables } \\
\hline Discontinuation of metformin & 0.0714 & beta $[0.0669 ; 0.8701]$ & Schweizer 2007 \\
\hline Discontinuation of vildagliptin & 0.0424 & $\operatorname{beta}[0.0395 ; 0.8930]$ & Schweizer 2007 \\
\hline Hypoglycemia - metformin & 0.0040 & $\operatorname{beta}[0.0016 ; 0.4032]$ & Schweizer 2007 \\
\hline Hypoglycemia - vildagliptin & 0.0058 & $\operatorname{beta}[0.0036 ; 0.6139]$ & Schweizer 2007 \\
\hline HbA $1 \mathrm{c}>7,0 \%$ - metformin & 0.6586 & $\operatorname{beta}[0.6665 ; 0.3454]$ & Schweizer 2007 \\
\hline HbA $1 \mathrm{c}>7,0 \%$ - vildagliptin & 0.7476 & $\operatorname{beta}[0.7502 ; 0.2533]$ & Schweizer 2007 \\
\hline \multicolumn{4}{|l|}{ Model 2 variables } \\
\hline TIA - control & 0.0036 & $\operatorname{beta}[0.0014 ; 0.4020]$ & Bolli 2009 \\
\hline TIA - vildagliptin & $1.00 \mathrm{E}-06$ & beta[2.168E-10;0.0002] & Bolli 2009 \\
\hline Stroke - control & 0.0054 & $\operatorname{beta}[0.0045 ; 0.8343]$ & Bolli 2009, Ferrannini 2009 \\
\hline Stroke - vildagliptin & 0.0006 & $\operatorname{beta}[0.0002 ; 0.3955]$ & Bolli 2009, Ferrannini 2009 \\
\hline PAD - control & 0.0007 & $\operatorname{beta}[0.0003 ; 0.3961]$ & Ferrannini 2009 \\
\hline PAD - vildagliptin & $1.00 \mathrm{E}-01$ & beta[1.016E-09;0.0010] & Ferrannini 2009 \\
\hline Discontinuation of control & 0.0709 & beta $[0.0705 ; 0.9234]$ & Ferrannini 2009, Filozof 2010 \\
\hline Discontinuation of vildagliptin & 0.0537 & $\operatorname{beta}[0.0531 ; 0.9352]$ & Ferrannini 2009, Filozof 2010 \\
\hline Hypoglycemia - control & 0.1095 & beta $[0.1091 ; 0.8877]$ & $\begin{array}{c}\text { Bolli 2009, Ferrannini 2009, } \\
\text { Filozof } 2010\end{array}$ \\
\hline Hypoglycemia - vildagliptin & 0.0137 & $\operatorname{beta}[0.0129 ; 0.9317]$ & $\begin{array}{c}\text { Bolli 2009, Ferrannini } 2009, \\
\text { Filozof } 2010\end{array}$ \\
\hline Heart failure - control & 0.0014 & $\operatorname{beta}[0.0007 ; 0.5108]$ & Ferrannini 2009 \\
\hline Heart failure - vildagliptin & 0.0014 & beta[0.0007;0.5065] & Ferrannini 2009 \\
\hline HbAlc $>7,0 \%$ - control & 0.6802 & $\operatorname{beta}[0.6845 ; 0.3219]$ & Filozof 2010 \\
\hline HbA1c $>7,0 \%$ - vildagliptin & 0.7037 & $\operatorname{beta}[0.7078 ; 0.2980]$ & Filozof 2010 \\
\hline $\mathrm{ACS}-$ control & 0.0048 & $\operatorname{beta}[0.0040 ; 0.8262]$ & Bolli 2009, Ferrannini 2009 \\
\hline ACS - vildagliptin & 0.0036 & $\operatorname{beta}[0.0026 ; 0.7411]$ & Bolli 2009, Ferrannini 2009 \\
\hline \multicolumn{4}{|l|}{ Model 3 variables } \\
\hline Colon adenoma - vildagliptin & 0.0001 & $\operatorname{beta}[0.0068 ; 92.3680]$ & Montilla 2014 \\
\hline Stroke - control & $3.2 \mathrm{E}-05$ & $\operatorname{beta}[0.0002 ; 7.6215]$ & Montilla 2014 \\
\hline Stroke - vildagliptin & 0.0001 & $\operatorname{beta}[0.0068 ; 92.3680]$ & Montilla 2014 \\
\hline Bladder cancer - vildagliptin & 0.0001 & $\operatorname{beta}[0.0068 ; 92.3680]$ & Montilla 2014 \\
\hline Colon cancer - control & 0.0001 & beta[0.0025;38.9946] & Montilla 2014 \\
\hline Colon cancer - vildagliptin & 0.0001 & beta$[0.0068 ; 92.3680]$ & Montilla 2014 \\
\hline Breast cancer - control & 0.0001 & $\operatorname{beta}[0.0025 ; 38.9946]$ & Montilla 2014 \\
\hline Pericardial effusion - control & $3.2 \mathrm{E}-05$ & $\operatorname{beta}[0.0002 ; 7.6215]$ & Montilla 2014 \\
\hline Hypoglycemia - control & 0.0117 & $\operatorname{beta}[0.0118 ; 0.9919]$ & Mathieu 2013 \\
\hline Hypoglycemia - vildagliptin & 0.0025 & beta $[0.0024 ; 0.9448]$ & Mathieu 2013 \\
\hline Renal failure - vildagliptin & 0.0001 & $\operatorname{beta}[0.0068 ; 92.3680]$ & Montilla 2014 \\
\hline Leukemia - control & 0.0001 & $\operatorname{beta}[0.0025 ; 38.9946]$ & Montilla 2014 \\
\hline Leukemia - vildagliptin & 0.0001 & beta$[0.0068 ; 92.3680]$ & Montilla 2014 \\
\hline Pneumonia - control & 0.0001 & beta $[0.0025 ; 38.9946]$ & Montilla 2014 \\
\hline $\operatorname{COSTS}(\mathrm{R} \$)^{\mathrm{a}}$ & & & \\
\hline
\end{tabular}




\begin{tabular}{|c|c|c|c|}
\hline \multicolumn{4}{|l|}{ Models variables } \\
\hline Outpatient T2DM & 26.2162 & $\operatorname{gamma}[0.2705 ; 0.0103]$ & SIA \\
\hline Outpatient hypoglycemia & 30.9205 & $\operatorname{gamma}[0.4238 ; 0.0137]$ & SIA \\
\hline Inpatient T2DM & 486.0846 & gamma[0.5056;0.0010] & $\mathrm{SIH}$ \\
\hline Inpatient hypoglycemia & 63.8444 & gamma[0.9194;0.0144] & SIH \\
\hline Metformin (tablet) & 0.0580 & gamma[19.1832;330.4888] & BPS \\
\hline Salary CHA & 185.3712 & gamma[38.4035;0.2072] & $\mathrm{PBH}$ \\
\hline Salary HSA & 317.7851 & $\operatorname{gamma}[6.2297 ; 0.0196]$ & PBH \\
\hline Salary nurse & 767.5083 & gamma[7.0584;0.0092] & $\mathrm{PBH}$ \\
\hline Salary doctor & $2,725.5172$ & gamma[4.2581;0.0016] & $\mathrm{PBH}$ \\
\hline Salary HST & 277.2010 & $\operatorname{gamma}[9.3583 ; 0.0338]$ & $\mathrm{PBH}$ \\
\hline Salary HSST & 617.8480 & gamma[4.7421;0.0077] & PBH \\
\hline Vildagliptin (tablet) & 1.9171 & gamma[2,215.93;1,155.8974] & BPS \\
\hline \multicolumn{4}{|l|}{ Model 2 variables } \\
\hline Outpatient TIA & 32.6335 & gamma[0.7721;0.0237] & SIA \\
\hline Outpatient stroke & 44.1113 & $\operatorname{gamma}[0.5516 ; 0.0125]$ & SIA \\
\hline Outpatient PAD & 52.9475 & $\operatorname{gamma}[0.4524 ; 0.0085]$ & SIA \\
\hline Outpatient heart failure & 117.2197 & $\operatorname{gamma}[0.2056 ; 0.0018]$ & SIA \\
\hline Outpatient ACS & 304.3038 & gamma[1.3264;0.0044] & SIA \\
\hline Inpatient TIA & 953.1707 & gamma[0.2602;0.0003] & $\mathrm{SIH}$ \\
\hline Inpatient stroke & $1,215.7729$ & gamma[0.2911;0.0002] & $\mathrm{SIH}$ \\
\hline Inpatient PAD & $2,526.9404$ & $\operatorname{gamma}[0.7360 ; 0.0003]$ & $\mathrm{SIH}$ \\
\hline Inpatient heart failure & $1,552.1003$ & $\operatorname{gamma}[0.1607 ; 0.0001]$ & $\mathrm{SIH}$ \\
\hline Inpatient ACS & $3,773.6034$ & $\operatorname{gamma}[0.7505 ; 0.0002]$ & $\mathrm{SIH}$ \\
\hline Control (tablet) & 0.4054 & gamma[44.497;109.7738] & BPS \\
\hline \multicolumn{4}{|l|}{ Model 3 variables } \\
\hline Outpatient colon adenoma & 132.2865 & gamma[5.7146;0.0432] & SIA \\
\hline Outpatient stroke & 44.1113 & gamma[0.5516;0.0125] & SIA \\
\hline Outpatient bladder cancer & 318.6474 & gamma[0.6069;0.0019] & SIA \\
\hline Outpatient colon cancer & 915.8832 & $\operatorname{gamma}[1.0348 ; 0.0011]$ & SIA \\
\hline Outpatient breast cancer & 518.3841 & gamma[1.8797;0.0036] & SIA \\
\hline Outpatient pericardial effusion & 44.1064 & $\operatorname{gamma}[0.7066 ; 0.0160]$ & SIA \\
\hline Outpatient renal failure & 62.8281 & $\operatorname{gamma}[0.1348 ; 0.0021]$ & SIA \\
\hline Outpatient leukemia & 168.0535 & gamma[1.2572;0.0075] & SIA \\
\hline Outpatient pneumonia & 26.7389 & $\operatorname{gamma}[0.4439 ; 0.0166]$ & SIA \\
\hline Inpatient colon adenoma & $3,481.8368$ & gamma[1.6286;0.0005] & $\mathrm{SIH}$ \\
\hline Inpatient stroke & $1,215.7729$ & gamma[0.2911;0.0002] & $\mathrm{SIH}$ \\
\hline Inpatient bladder cancer & $1,227.4688$ & $\operatorname{gamma}[0.4330 ; 0.0004]$ & $\mathrm{SIH}$ \\
\hline Inpatient colon cancer & $1,157.0266$ & gamma[0.6953;0.0006] & $\mathrm{SIH}$ \\
\hline Inpatient breast cancer & 781.2555 & gamma[0.3663;0.0005] & $\mathrm{SIH}$ \\
\hline Inpatient pericardial effusion & $2,745.2068$ & $\operatorname{gamma}[0.5862 ; 0.0002]$ & $\mathrm{SIH}$ \\
\hline Inpatient renal failure & $1,835.3242$ & $\operatorname{gamma}[0.2704 ; 0.0001]$ & $\mathrm{SIH}$ \\
\hline Inpatient leukemia & $2,494.5476$ & $\operatorname{gamma}[0.4101 ; 0.0002]$ & $\mathrm{SIH}$ \\
\hline Inpatient pneumonia & $1,008.7475$ & gamma[0.2766;0.0003] & $\mathrm{SIH}$ \\
\hline Control (tablet) & 1.9082 & gamma[37,629.38;1,9719.8255] & BPS \\
\hline
\end{tabular}


${ }^{a}$ Monetary amounts in Brazilian currency. Conversion factor to purchasing power parity: 1.73 (local currency per international \$), World Bank, 2014.

ACS: acute coronary syndrome; BPS: Brazilian Health Prices Database; CHA: community health agent; T2DM: type 2 diabetes mellitus; HbAlc: glycosylated hemoglobin A1c; HSA: health service agent; HSST: health service superior technician; HST: health service technical; PAD: peripheral artery disease; PBH: Municipality of Belo Horizonte; PE: pericardial effusion; SIA: Brazilian Outpatient Information System; SIH: Brazilian Hospital Information System; TIA: transient ischemic attack.

In models 1 and 2, patients who discontinued treatment due to adverse events, or remained with $\mathrm{HbAlc}$ higher than $7.0 \%$, followed the hypothetical cohort with rescue therapy considering the same transition probabilities for the other stages, except for the increase of, respectively, $10 \%$ and $30 \%$ in the risk of death. Treatment discontinuation due to adverse events was considered only in the first two years of the cohort. In Model 3, because there are insufficient observational data to model these two clinical conditions, the patients remained in the T2DM no complications stage until they went on to some modelled complication.

According to the literature, the average ages of entry for patients in the hypothetical cohorts were 53, 58 and 62 years for models 1, 2 and 3, respectively. Since death probabilities in these studies were lower compared to the Brazilian population and lower for vildagliptin compared to controls, the overall death probability for each age in the Brazilian population was considered, in 2014, for the groups treated with vildagliptin. For the comparator groups, the same probability has been multiplied by the ratio of its superiority in relation to the value of vildagliptin obtained in the study (Table 2 ).

Table 2. Annual probability of death used in the models for evaluation of vildagliptincontaining treatments for Type 2 Diabetes Mellitus.

\begin{tabular}{|c|c|c|c|c|c|c|}
\hline \multirow{2}{*}{ Age } & \multicolumn{2}{|c|}{ Model 1 ${ }^{\mathrm{a}}$} & \multicolumn{2}{|c|}{ Model 2 ${ }^{\text {b }}$} & \multicolumn{2}{|c|}{ Model 3 ${ }^{c}$} \\
\hline & Vildagliptin & Metformin & Vildagliptin & Control & Vildagliptin & Control \\
\hline 53 & 0.0068 & 0.0140 & & & & \\
\hline 54 & 0.0073 & 0.0150 & & & & \\
\hline 55 & 0.0078 & 0.0161 & & & & \\
\hline 56 & 0.0084 & 0.0173 & & & & \\
\hline 57 & 0.0090 & 0.0186 & & & & \\
\hline 58 & 0.0097 & 0.0199 & 0.0097 & 0.0131 & & \\
\hline 59 & 0.0104 & 0.0214 & 0.0104 & 0.0140 & & \\
\hline 60 & 0.0111 & 0.0229 & 0.0111 & 0.0150 & & \\
\hline 61 & 0.0119 & 0.0246 & 0.0119 & 0.0161 & & \\
\hline 62 & 0.0128 & 0.0265 & 0.0128 & 0.0173 & 0.0128 & 0.0155 \\
\hline 63 & & & 0.0139 & 0.0187 & 0.0139 & 0.0166 \\
\hline 64 & & & 0.0150 & 0.0203 & 0.0150 & 0.0178 \\
\hline 65 & & & 0.0163 & 0.0220 & 0.0163 & 0.0191 \\
\hline 66 & & & 0.0176 & 0.0238 & 0.0176 & 0.0206 \\
\hline 67 & & & 0.0192 & 0.0259 & 0.0192 & 0.0222 \\
\hline 68 & & & & & 0.0209 & 0.0241 \\
\hline 69 & & & & & 0.0228 & 0.0261 \\
\hline 70 & & & & & 0.0248 & 0.0283 \\
\hline 71 & & & & & 0.0270 & 0.0307 \\
\hline
\end{tabular}

${ }^{a}$ Vildagliptin monotherapy vs. metformin monotherapy.

${ }^{b}$ Vildagliptin combined with metformin vs. metformin combined with other hypoglycemic agent.

${ }^{\mathrm{c}}$ Dual vildagliptin-containing treatment vs. other dual treatment. 
To balance the timeliness and data consistency, all monetary values used are for 2014 . Medicines prices considered in the study were taken from the Integrated System of Administration and General Services (Siasg) through the Health Prices Database (BPS) [26]. Through the Hospital Information System (SIH) [34] and the Outpatient Information System (SIA) [35], the average costs for hospitalisation and outpatient services for each identified transition states were obtained. For these costs, means and standard deviations were calculated (Table 1).

Based on the city of Belo Horizonte, Minas Gerais, as a representative city within Brazil, average remuneration levels were obtained for health professionals who participate directly in the care of patients affected by T2DM in primary care. This includes doctors, nurses, community health care workers as well as technicians and other relevant health care workers treating these patients technician [36]. Considering a monthly follow, half an hour per month was considered the equivalent of the remuneration of each professional for the total annual value (Table 1).

Models 1 and 2 considered rescue therapy in cases of discontinuation due to adverse events and $\mathrm{HbA} 1 \mathrm{c}$ higher than $7.0 \%$. For Model 1, this means adding metformin $850 \mathrm{mg}$ b.i.d. to vildagliptin $50 \mathrm{mg}$ b.i.d. and the increase of monotherapy with metformin $850 \mathrm{mg}$ from b.i.d. to t.i.d. In Model 2, metformin $850 \mathrm{mg}$ increased from b.i.d. to t.i.d in combination with vildagliptin or control (pioglitazone, glimepiride or gliclazide).

In health technology economic evaluations, the use of a discount rate in cost and effectiveness analyses is recommended. Where there is often a difference in time between the investment in health service resources and benefits in health associated with the investment, we used the arbitrary rate of 5\% for costs and effects, recommended by the Ministry of Health in Brazil when the analysis is for longer than one year [37].

Effectiveness was measured in life years (LY). A LY was computed for each cycle in which patients remained free of complications that resulted in either secondary or tertiary care. We also considered, according to each cycle, costs related to their transition states.

At the end of the hypothetical cohort, costs and effectiveness were calculated according to the different interventions. For each intervention, the cost-effectiveness ratios (CER) were calculated. CER will correspond to the monetary value that will need to be invested in a particular treatment in order to obtain a LY under primary care. In this cost-effectiveness analysis, currency values were adjusted for purchasing power parity (PPP), whose conversion factor was approximately 1.73 (local currency for international \$) in 2014 [38]. Adjusted values were expressed with currency symbol \$.

In this study, the incremental cost-effectiveness ratio (ICER) reflects the cost of a LY gained or one hypoglycemia episode avoided compared to other treatments. ICER is the ratio of the differences in cost and effectiveness between the assessed therapeutic alternatives. An intervention is considered cost-effective in Brazil if the ICER value is lower than the Brazilian gross domestic product (GDP) per capita, equivalent to $\$ 16,210.24$ in 2014 [39].

Results obtained by economic evaluations in health are subjected to uncertainties, which are mainly justified by the limited data available [37]. In this study, a probabilistic sensitivity analysis was conducted to assess how far the uncertainties of variables interfere with an outcome. Consequently, a Monte Carlo simulation was performed to generate a sample of 
1,000 interactions between variables considering willingness to pay between half and one GDP per capita. Beta distributions were used for each progression data of the disease and gamma distributions for each allocated costs. For presenting random values between 0 and 1 , beta distribution has its recommended use to simulate distribution of transition probabilities of hypothetical cohorts. However, for the cost data, which are not random and cannot be negative, the use of gamma distribution for sensitivity analysis is recommended [40].

\section{Results}

At the end of ten years, $22.2 \%$ of patients who were treated with vildagliptin monotherapy and $27.0 \%$ of those using only metformin remained without complications and with $\mathrm{HbAlc}$ levels lower than $7.0 \%$. For treatments in combination, proportions were $23.3 \%$ and $15.2 \%$ for metformin associated with, respectively, vildagliptin and control, i.e. pioglitazone, glimepiride or gliclazide. Considering observational data, $81.3 \%$ and $71.9 \%$ of patients who received vildagliptin and control, respectively, remained without complications (Table 3). Most of patients showed HbA1c higher than 7.0\% at the end of follow-up in models where this clinical situation was a transition state. Comparing monotherapies, the proportion of patients treated with vildagliptin in this situation was $26.8 \%$ higher compared to metformin. As for the association between vildagliptin and metformin, the superiority was $56.1 \%$ compared to control (Table 3 ).

Table 3. Patients proportion in each transition state at the end of the hypothetical cohort.

\begin{tabular}{lcccccc}
\hline \multirow{2}{*}{ Stage } & \multicolumn{2}{c}{ Model 1 $^{\mathbf{a}}$} & \multicolumn{2}{c}{ Model 2 $^{\mathbf{b}}$} & \multicolumn{2}{c}{ Model 3 $^{\mathbf{c}}$} \\
\cline { 2 - 7 } & Vildagliptin & Metformin & Vildagliptin & Control & Vildagliptin & Control \\
\hline T2DM without complications & 0.2223 & 0.2696 & 0.2330 & 0.1521 & 0.8126 & 0.7193 \\
Discontinuation for adverse events & 0.0000 & 0.0000 & 0.0000 & 0.0000 & & \\
HbA1c $>$ 7,0\% & 0.6621 & 0.5223 & 0.5580 & 0.3574 & & \\
Hypoglycemia & 0.0137 & 0.0120 & 0.0361 & 0.2590 & 0.0230 & 0.1007 \\
Death & 0.1019 & 0.1960 & 0.1378 & 0.1513 & 0.1605 & 0.1771 \\
Acute coronary syndrome & & & 0.0223 & 0.0242 & & \\
Heart failure & & 0.0090 & 0.0073 & & \\
Stroke & & 0.0037 & 0.0272 & 0.0007 & 0.0003 \\
Transient ischemic attack & & 0.0000 & 0.0180 & & \\
Peripheral artery disease & & 0.0000 & 0.0036 & & 0.0007 & 0.0000 \\
Renal failure & & & & 0.0007 & 0.0006 \\
Colon cancer & & & & 0.0007 & 0.0000 \\
Colon adenoma & & & & 0.0007 & 0.0006 \\
Leukemia & & & & & 0.0007 & 0.0000 \\
Bladder cancer & & & & 0.0000 & 0.0006 \\
Pneumonia & & & & 0.0000 & 0.0006 \\
Breast cancer & & & & 0.0000 & 0.0003 \\
Pericardial effusion & & & & & & \\
\hline
\end{tabular}

a Vildagliptin monotherapy vs. metformin monotherapy.

${ }^{\mathrm{b}}$ Vildagliptin combined with metformin vs. metformin combined with other hypoglycemic agent.

${ }^{c}$ Dual vildagliptin-containing treatment vs. other dual treatment.

Among the complications evaluated in the model, acute coronary syndrome showed a higher proportion at the end of the model, with $2.2 \%$ for patients who were treated with the 
combination of vildagliptin and metformin and $2.4 \%$ for controls. A higher proportion than $1 \%$ was observed only for stroke and transient ischemic attack in patients treated with metformin associated with control. In all models, the proportion of death was lower in groups treated with vildagliptin, with inferiority ranging between $8.9 \%$ and $48.0 \%$ (Table 3 ).

In all models, the total cost of patients' treatment using vildagliptin was greater than those who used controls. Values were $27.0 \%, 22.9 \%$ and $12.2 \%$ higher considering the models 1,2 and 3, respectively. On the other hand, treatments containing vildagliptin offered higher LYs with no complications, being, respectively, $4.3 \%, 19.8 \%$ and $5.3 \%$ longer than controls. Differences between cost and effectiveness of treatment with vildagliptin were higher in all comparisons, being $21.7 \%$ higher in the comparison of monotherapy with metformin, $2.6 \%$ higher between combinations and $6.4 \%$ above considering observational data (Table 4 ).

Table 4. Cost-effectiveness of vildagliptin-containing treatments for Type 2 Diabetes Mellitus

\begin{tabular}{lcccccc}
\hline Treatment & Cost (\$) & $\begin{array}{c}\text { Incremental } \\
\text { cost (\$) }\end{array}$ & $\begin{array}{c}\text { Effectiveness } \\
(\mathbf{L Y})\end{array}$ & $\begin{array}{c}\text { Incremental } \\
\text { effectiveness } \\
(\mathbf{L Y})\end{array}$ & CER (\$) & ICER (\$) \\
\hline Model 1 & & & & & & \\
Metformin & $23,089.40$ & & 7.23 & & $3,159.55$ & \\
Vildagliptin & $29,228.68$ & $6,139.27$ & 7.54 & 0.31 & $3,878.25$ & $19,735.91$ \\
Model 2 & & & & & & \\
Control & $24,123.31$ & & 6.01 & & $4,012.62$ & \\
Vildagliptin & $29,651.22$ & $5,527.91$ & 7.20 & 1.19 & $4,119.26$ & $4,659.62$ \\
Model 3 & & & & & & \\
Control & $26,175.59$ & & 6.92 & & $3,783.67$ & \\
Vildagliptin & $29,373.38$ & $3,197.80$ & 7.29 & 0.37 & $4,029.03$ & $8,587.09$ \\
\hline
\end{tabular}

\footnotetext{
${ }^{a}$ Vildagliptin monotherapy vs. metformin monotherapy.

${ }^{\mathrm{b}}$ Vildagliptin combined with metformin vs. metformin combined with other hypoglycemic agent.

${ }^{c}$ Dual vildagliptin-containing treatment vs. other dual treatment.

$\$$ : Currency values were adjusted for purchasing power parity (PPP). Conversion factor to purchasing power parity: 1.73 (local currency per international \$), World Bank, 2014; LY: life years.
}

ICER of vildagliptin monotherapy compared to metformin was US\$19,735.91, which means $21.7 \%$ above the cost-effectiveness threshold set for this study based on the Brazilian context. On the other hand, it was below GDP per capita in the other two comparisons. Considering the comparison between metformin combined with vildagliptin or other medicines, the ICER was equivalent to $28.7 \%$ of the considered threshold, totalizing $\$ 4,659.62$. For the comparison involving observational data, the ICER was from $\$ 8,587.09$, corresponding to $53.0 \%$ of GDP per capita (Table 4).

According to the sensitivity analysis, considering willingness to pay between half and one GDP per capita, none of the simulations for treatment with vildagliptin had a higher 
proportion of presenting a lower CER compared to controls. The vildagliptin CER was lower than the control CER in $0.5 \%$ to $12.2 \%$ of the simulations in Model 1, 23.4\% to $28.9 \%$ in Model 2 and 3.0\% to 5.0\% in Model 3 (Figure 1).

Figure 1. Probabilistic sensitivity analysis for the cost-effectiveness of vildagliptin-containing treatments for Type 2 Diabetes Mellitus. (a) Vildagliptin monotherapy vs. metformin monotherapy; (b) Vildagliptin combined with metformin vs. metformin combined with other hypoglycemic agent; (c) Dual vildagliptin-containing treatment vs. other dual treatment.

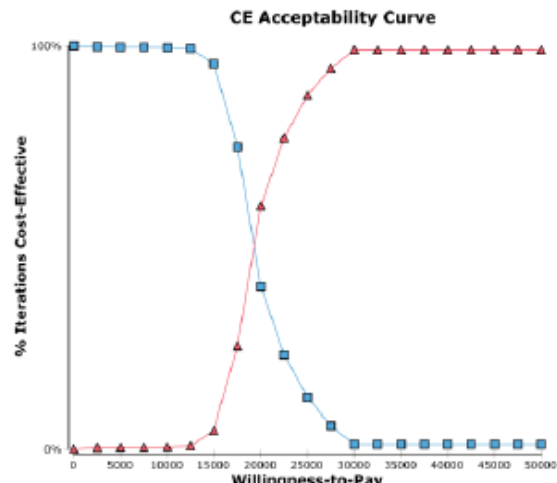

(a)

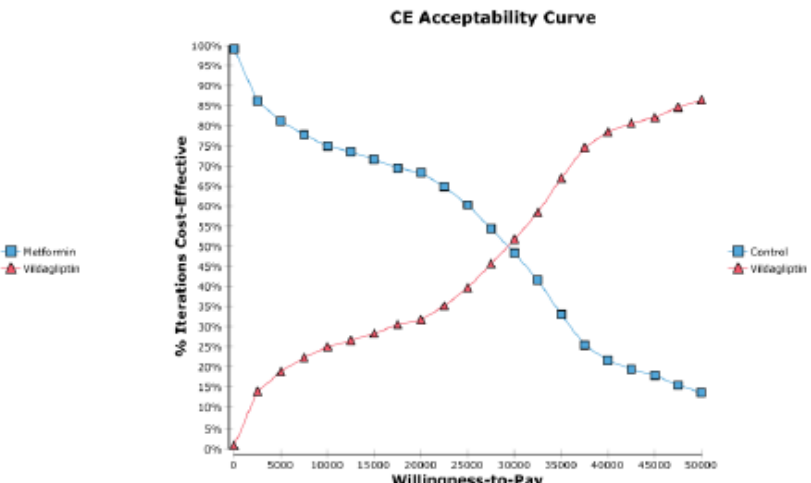

(b)

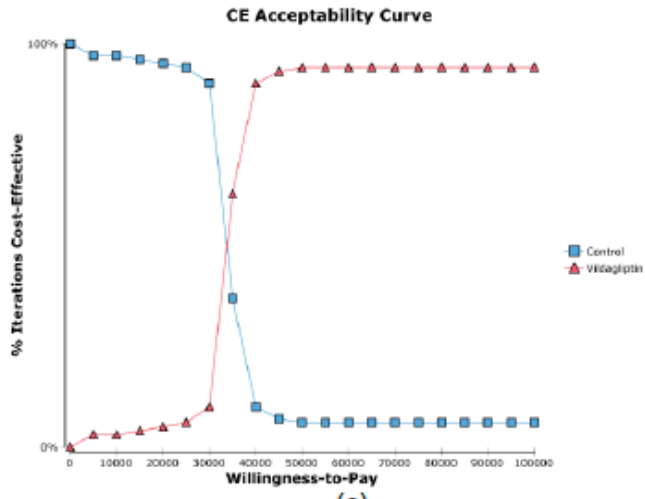

(c)

In the ICER analysis, these were higher than the willingness to pay in most simulations involving treatment with vildagliptin. In addition, in these simulations vildagliptin was more expensive and more effective. The simulations proportion in this situation was $86.8 \%, 65.9 \%$ and $89.0 \%$, respectively, in the models 1,2 and 3 (Table 5). 
Table 5. ICER simulations from the probabilistic sensitivity analysis for the cost-effectiveness of vildagliptin-containing treatments for Type 2 Diabetes Mellitus.

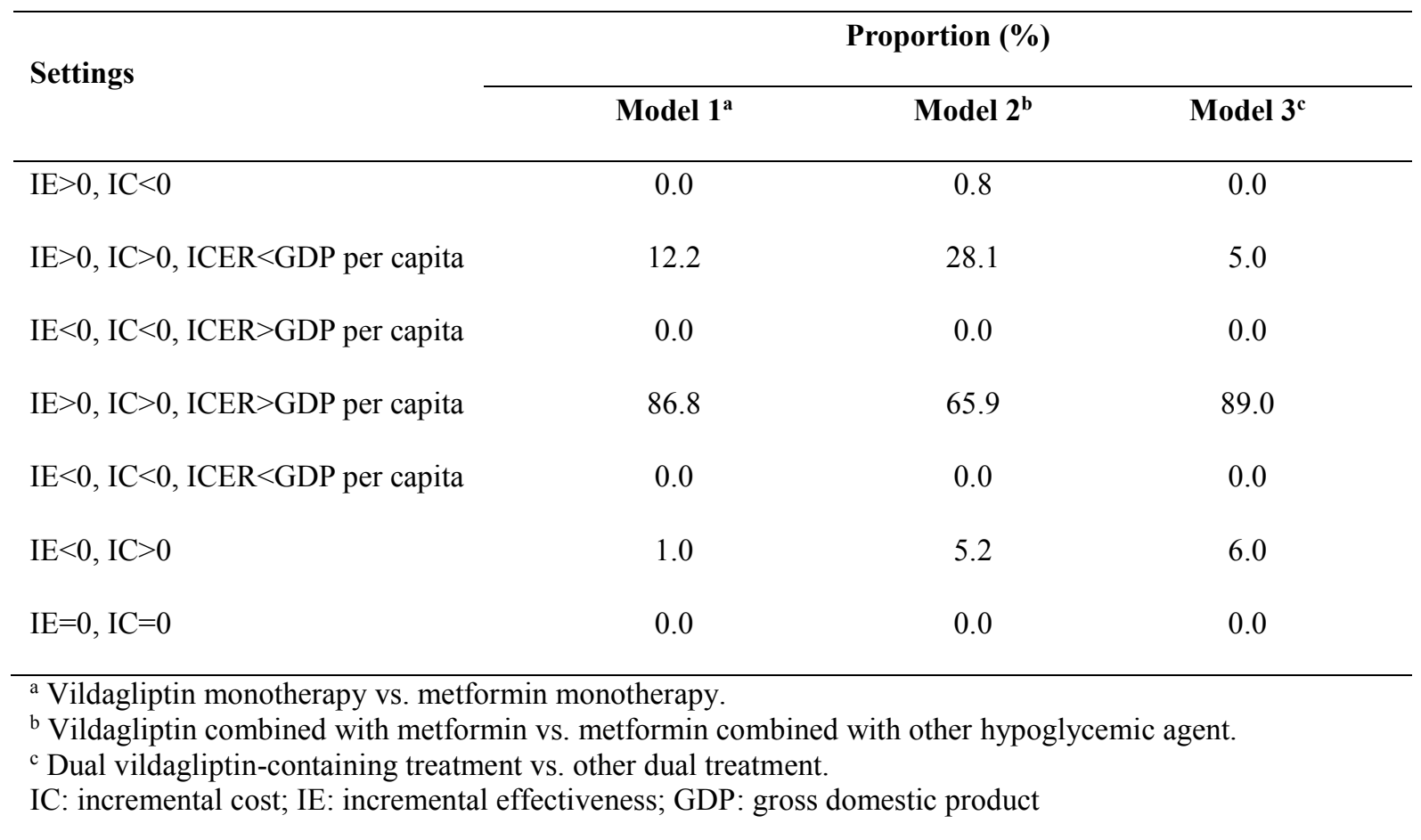

\section{Discussion}

Despite treatments with vildagliptin offering longer life without complications, differences compared to controls were small in the comparison with metformin or among observational data. Difference between treatments combined with metformin was the largest, meaning approximately a year and 2 months longer life for patients who received vildagliptin. However in all comparisons, treatment's costs with vildagliptin were higher in relation to controls especially since metformin is available as a low cost generic in Brazil.

Considering data used and willingness to pay, the use of vildagliptin in T2DM treatment is not cost-effective using the definitions in Brazil. This is even more so if a cost/QALY ICER was used, which is normally the metric used by health authorities using cost effectiveness evaluations in their decision making [8,41-45]. Compared with metformin, the ICER for vildagliptin was higher than GDP per capita. Comparing its combination with metformin and with other drugs, despite the ICER being lower than GDP per capita, it is predominantly higher than the willingness to pay on the uncertainties of variables used. For the same reason, treatments involving vildagliptin cannot be considered cost-effective based on available data.

As previously mentioned, oral hypoglycemic agents provided by the Brazilian public health system are metformin, glibenclamide and gliclazide. In addition to these, regular and NPH insulins are included in the essential drug lists for treatment of people living with Diabetes Mellitus. Some Brazilian states have also included insulin analogues in their supply lists [25]. Considering the comparison between monotherapies, vildagliptin cannot currently be recommended as a substitute of metformin as monotherapy in line with current treatment guidelines $[10,13,22]$. In the assessment of metformin combinations, it is not possible to conclude about the superiority of vildagliptin compared to gliclazide, because we needed to include data from other medicines in vildagliptin-comparator modelling. The study of Filozof et al (2010) was the data source of the combination of gliclazide and metformin, whose 
variables extracted were $\mathrm{HbA} 1 \mathrm{c}>7,0 \%$, hypoglycemia, discontinuation due to adverse events and overall death [27]. In fact, the mean values of this study were lower for the combination of metformin and gliclazide than vildagliptin combined with metformin, except for hypoglycemia. The similarity between the combinations in HbAlc lowering was the conclusion of the study.

Comparisons involving observational data were made even though there is acknowledged heterogeneity in the patients enrolled. Two studies were used, one of which included any oral hypoglycemic agent as a control and the other considered sitagliptin - a dipeptidyl peptidase4 inhibitor currently not provided by Brazilian public health system. Furthermore, most of data used in the model was extracted from this study, being the only data source of progression to complications. Consequently, in this evaluation, vildagliptin is basically compared to other DPP-4 inhibitor. Therefore, its ICER should be interpreted with caution for inclusion in the health system drugs list.

Health economic models are a simplification of what is considered as treatment and actual clinical prognoses. In this way, treatment of a disease is not typically fully addressed in a multifactorial complexity. Economic analysis based on models helps in decision making by those responsible for coordinating programs and health services within finite resources. Factors, parameters and assumptions considered in the model, as well the non-modeled, should be considered for decision making.

We accept a number of limitations with our analysis and review. These include the fact that the effectiveness and efficacy data obtained were from non-Brazilian as there was no clinical trial or observational data including patients from Brazil populations. We also only included studies with longer term follow-up for the reasons discussed in the methodology. In addition, available studies typically only had a short follow-up period. In this way, clinical data were extrapolated until the end of the hypothetical cohort. Literature on the efficacy and effectiveness of vildagliptin is scarce, although approved by the Brazilian regulatory agency in 2007. Most studies comprise only 24 weeks of follow-up. Richter et al (2008), in a systematic review concerning DPP-4 inhibitors for the treatment of T2DM published by Cochrane Collaboration, indicated the urgent need for data about safety and follow up for long periods to aid decision making [46].

Shortage of this data is acknowledged in the models presented, implying the potential underestimation of disease complications and treatment costs. Waugh et al (2010), in a systematic review and economic evaluation of new medications for glycemic control in the UK perspective [47], included only one 24-week study, comparing metformin combined with vildagliptin or pioglitazone. The results of 52 weeks were published by Bolli et al (2009) and included in the models presented in this study [25]. In the economic model, patients' starting age was 58 years and the follow-up duration was 40 years. Effectiveness ranged from 8.56 years for men and 9.43 years for women. Considering that life expectancy of Brazilian population is lower than in UK, and that the model presented here has a time horizon of 10 years, it seems reasonable that effectiveness results ranged between 6.01 and 7.54 years.

We are also aware that we only look at ICERs based on LY saved and not cost/QALYs in our research. From the perspective of Portuguese health system, Viriato et al (2014) evaluated the cost-effectiveness between vildagliptin and metformin compared to metformin with sulphonylurea in a period of 40 years of follow-up. For this, they used the UKPDS Outcomes Model - model based on data from 30-year United Kingdom Prospective Diabetes Study 
carried out in English population [48]. Therapeutic alternatives demonstrated similar clinical results, with an increase of $2.3 \%$ in the quality adjusted life years with the use of vildagliptin (5.7681 vs. 5.6401). However, this alternative increased spending by $8.8 \%$ ( $€ 14,409$ vs. $€ 13,248$ ), providing an ICER of $€ 9,072$ [49]. Costs and effectiveness of the different therapeutic alternatives were lower than observed in our study. This may be due to the fact that Viriato et al did not consider costs with health professionals in their model, but considered different clinical complications and having adjusted life years to their quality.

Regarding the Brazilian context, an evaluation was recently performed with saxagliptin compared to rosiglitazone and pioglitazone, all combined with metformin, from the perspective of private health insurance companies. This study considered the clinical and economic data of insurers' records over a three-year time horizon. In all comparisons, the authors considered saxagliptin was cost-saving when combined with metformin versus the glitazone combinations. However, they did not research saxagliptin as monotherapy [50]. In a recent systematic review summarizing the results of the cost-effectiveness assessments of gliptins either as monotherapy or in combination, the authors concluded that gliptins combined with metformin are a cost-effective option compared to sulfonylureas and insulin. However, the quality of these studies was low and there are few studies free of conflicts of interest [51].

In another recent review, the authors considered gliptins cost-effective as add-on to metformin compared to sulfonylureas. However, the gliptins were not cost-effective when compared to GLP-1 receptor agonists and insulin analog glargine [52]. There were also concerns that the analyses were based on studies financed by the manufacturers. In a further cost-effectiveness evaluation of combined treatments with metformin, despite no significant differences in effectiveness and costs, dapagliflozin was considered cost-effective compared to gliptins from the UK Healthcare System Perspective [53].

In view of the current cost of US\$1.11 for a vildagliptin tablet and US\$0.03 for a metformin tablet in Brazil, only a dramatic reduction in the price of vildagliptin would make this treatment become cost-effective in Brazil as monotherapy. Despite recent publications on the benefits of dual treatment with gliptins and metformin, doubts still remain about the choice of vildagliptin over other gliptins as well as the overall safety of the gliptins [14-18]. The lack of safety data precludes the proper assessment of complications associated with this disease or other potential events associated with vildagliptin and their costs. Since the first register of vildagliptin, there has been concern about their limited effectiveness and the potential increased risk of patients experiencing cardiac and liver disorders, infections, pancreatitis, anaphylactic reactions, intestinal obstruction, bullous pemphigoid and neoplasms [54]. Because of the uncertainties about its safety, the FDA has not currently registered vildagliptin. As a result, still a concern in Brazil.

More studies of comparative effectiveness and safety are needed, using real-life data to improve our knowledge of vildagliptin especially in Latin American countries such as Brazil. Long-term evidence on clinical outcomes, safety and economic implications of new antidiabetic drugs are limited in the literature. Such evidence is even more limited on the direct comparison between medicines not grouped by pharmacological class [55]. Budgetary and logistical impact assessments will also aid decision making. 


\section{Conclusion}

Considering the clinical and monetary data from the treatment of T2DM patients, monotherapy with vildagliptin is not cost-effective compared to the monotherapy with metformin. In combination with metformin, vildagliptin demonstrated a low ICER in relation to other controls. However, sensitivity analysis identified a higher probability of this value to be more expensive than the willingness to pay threshold in Brazil, as well as in the analysis involving observational data comparing vildagliptin combinations in relation to other combinations between two oral hypoglycemic agents. Consequently, the incorporation of vildagliptin or its combination with metformin is currently not recommended for the Brazilian Health Care System. This may change as more long term data becomes available, especially safety data given current concerns, and ICER thresholds change. In addition, more studies of comparative effectiveness are needed using Brazilian real-life data to further assess the safety, effectiveness and cost-effectiveness of vildagliptin especially in combination with metformin. This also includes the generation of cost-utility data in the future. These are considerations for the future.

\section{Expert commentary}

The prevalence and expenditure on patients living with type 2 diabetes mellitus (T2DM) is increasing challenging healthcare systems especially those striving to provide universal healthcare. Typically guidelines for these patients, including Brazil, have metformin and sulfonylureas such as glibenclamide and gliclazide first line followed by insulin if needed. More recently, vildagliptin as monotherapy, or combined with metformin, has the potential to help achieve glycemic control as well as decrease episodes of hypoglycaemia and peripheral edema. However, there are concerns with its cost-effectiveness in Brazil where new treatments are considered as cost-effective at between half and one GDP per capita. Developed models showed that the use of vildagliptin increased life by a mean of 0.31 years compared to metformin and 1.19 more life years when combined with metformin when compared to other metformin combinations. However, despite reducing the occurrence of hypoglycemic events and increasing life expectancy, treatments for patients with T2DM containing vildagliptin are not currently considered cost-effective from the perspective of the Brazilian Health System.

\section{Five-year perspective}

It is likely that metformin and sulfonylureas will remain first choice treatments for patients with T2DM in Brazil over the next 5 years given the published evidence and their continued low costs. For patients where these medications are no longer sufficient for glycemic control, insulin administration or additional oral treatments with the gliptins such as vildagliptin will increasingly be used. New studies will provide insights into the safety, the risk of anaphylactic reactions as well as the potential for increased infections, pancreatitis and bullous pemphigoid with vildagliptin. However, unless new evidence points to an improved safety profile and effectiveness, it is unlikely that vildagliptin will be included within the Public Health System in Brazil unless the economic thresholds appreciably change. 


\section{Key issues:}

- The prevalence and costs associated with Type 2 diabetes is increasing. New treatents are welcomed; however they need to be cost-effective to be affordable within public healthcare systems

- Considering the willingness to pay up to a per capita GDP, vildagliptin monotherapy is not currently considered cost-effective compared to metformin monotherapy within the Brazilian public healthcare system

- Despite the low ICER of vildagliptin combined with metformin compared to other metformin combinations, we identified a higher probability of this value to be above the willingness to pay threshold based on Markov models and simulations

- Involving observational data, despite the low ICER, vildagliptin-containing treatments have again a lower probability to be below the cost-effectiveness threshold.

- Incorporation of vildagliptin or its combination with metformin is not currently recommended for the Brazilian Health System. This may change, especially for vildagliptin combined with metformin, once more long-term safety and outcome are reported.

\section{Acknowledgements and conflicts of interest}

The research was supported by the Research Group in Pharmacoepidemiology of the Federal University of Minas Gerais (UFMG). The authors declare that they have no conflicts of interest associated with this manuscript.

\section{Funding}

Gustavo Laine Araujo de Oliveira has received scholarship from the Brazilian Federal Agency for the Support and Evaluation of Graduate Education (Capes). This work was funded by National Scientific and Technological Development Council $(\mathrm{CNPq})$ and the Foundation of Support Research of the State of Minas Gerais (FAPEMIG). The write-up was in part supported by a Newton Advanced Fellowship awarded to Professor Augusto Afonso Guerra Junior by the Academy of Medical Sciences, through the UK Government's Newton Fund program.

\section{References/ supporting data}

$*=$ of important; $* *$ of considerable importance

1. World Health Organization. Global Report on Diabetes. Geneva: World Health Organization; 2016. 86 p.

2. International Diabetes Federation. IDF Diabetes Atlas. 7th ed. Brussels: International Diabetes Federation; 2015.

3. Kassahun T, Eshetie T, Gesesew H. Factors associated with glycemic control among adult patients with type 2 diabetes mellitus: a cross-sectional survey in Ethiopia. BMC Res Notes. 2016 Dec 9;9(1):78.

4. Brasil. Relação Nacional de Medicamentos Essenciais: RENAME 2014. 9th ed. Brasília: Ministério da Saúde; 2015. 228 p. 
5. UK Prospective Diabetes Study Group. Tight blood pressure control and risk of macrovascular and microvascular complications in type 2 diabetes: UKPDS 38. BMJ. 1998 Sep 12;317(7160):703-13.

* Important data about the association between diabetes and cardiovascular events.

6. Remuzzi G, Macia M, Ruggenenti P. Prevention and Treatment of Diabetic Renal Disease in Type 2 Diabetes: The BENEDICT Study. J Am Soc Nephrol. 2006 Apr 1;17(4_suppl_2):S90-7.

7. Collins R, Armitage J, Parish S, Sleigh P, Peto R, Heart Protection Study Collaborative Group. MRC/BHF Heart Protection Study of cholesterol-lowering with simvastatin in 5963 people with diabetes: a randomised placebo-controlled trial. Lancet. 2003 Jun;361(9374):2005-16.

8. Godman B, Malmström RE, Diogene E, Gray A, Jayathissa S, Timoney A, et al. Are new models needed to optimize the utilization of new medicines to sustain healthcare systems? Expert Rev Clin Pharmacol. 2015 Jan 2;8(1):77-94.

9. Bolen S, Tseng E, Hutfless S, Segal JB, Suarez-Cuervo C, Berger Z, et al. Diabetes Medications for Adults With Type 2 Diabetes: An Update [Internet]. Rockville (MD): AHRQ Comparative Effectiveness Reviews; 2016.

10. Hippisley-Cox J, Coupland C. Diabetes treatments and risk of heart failure, cardiovascular disease, and all cause mortality: cohort study in primary care. BMJ. 2016 Jul 12;i3477.

** Real-life data on safety outcomes.

11. Wise J. Metformin is backed as first line therapy for type 2 diabetes. BMJ. 2016 Apr $19 ;$ i2236.

12. Maruthur NM, Tseng E, Hutfless S, Wilson LM, Suarez-Cuervo C, Berger Z, et al. Diabetes Medications as Monotherapy or Metformin-Based Combination Therapy for Type 2 Diabetes. Ann Intern Med. 2016 Jun 7;164(11):740.

13. Shih C-J, Chen H-T, Kuo S-C, Ou S-M, Chen Y-T. Cardiovascular Outcomes of Dipeptidyl Peptidase-4 Inhibitors in Elderly Patients With Type 2 Diabetes: A Nationwide Study. J Am Med Dir Assoc. 2016 Jan;17(1):59-64.

14. Fisman EZ, Tenenbaum A. Antidiabetic treatment with gliptins: focus on cardiovascular effects and outcomes. Cardiovasc Diabetol. 2015 Dec 29;14(1):129. 
15. McInnes G, Evans M, Del Prato S, Stumvoll M, Schweizer A, Lukashevich V, et al. Cardiovascular and heart failure safety profile of vildagliptin: a meta-analysis of 17 000 patients. Diabetes, Obes Metab. 2015 Nov;17(11):1085-92.

** Important data on the risks of DPP-4 inhibitors.

16. Karagiannis T, Bekiari E, Boura P, Tsapas A. Cardiovascular risk with DPP-4 inhibitors: latest evidence and clinical implications. Ther Adv Drug Saf. 2016 Apr $1 ; 7(2): 36-8$.

17. Thompson PL, Davis TME. Cardiovascular Effects of Glucose-Lowering Therapies for Type 2 Diabetes: New Drugs in Perspective. Clin Ther. 2016 Nov 15;[Epub ahead of print].

18. Barkas F, Elisaf M, Tsimihodimos V, Milionis H. Dipeptidyl peptidase-4 inhibitors and protection against stroke: A systematic review and meta-analysis. Diabetes Metab. 2016 Dec 1;[Epub ahead of print].

19. Cramer JA, Benedict Á, Muszbek N, Keskinaslan A, Khan ZM. The significance of compliance and persistence in the treatment of diabetes, hypertension and dyslipidaemia: a review. Int J Clin Pract. 2007 Nov 5;62(1):76-87.

20. Awodele O, Osuolale J. Medication adherence in type 2 diabetes patients: study of patients in Alimosho General Hospital, Igando, Lagos, Nigeria. Afr Health Sci. 2015 May 28;15(2):513.

21. García-Pérez L-E, Álvarez M, Dilla T, Gil-Guillén V, Orozco-Beltrán D. Adherence to Therapies in Patients with Type 2 Diabetes. Diabetes Ther. 2013 Dec 30;4(2):175-94.

22. Sicras-Mainar A, Navarro-Artieda R. Healthcare Costs of the Combination of Metformin/Dipeptidyl Peptidase-4 Inhibitors Compared with Metformin/Other Oral Antidiabetes Agents in Patients with Type 2 Diabetes and Metabolic Syndrome. Diabetes Technol Ther. 2014 Nov;16(11):722-7.

23. Mari A, Sallas WM, He YL, Watson C, Ligueros-Saylan M, Dunning BE, et al. Vildagliptin, a Dipeptidyl Peptidase-IV Inhibitor, Improves Model-Assessed $\beta$-Cell Function in Patients with Type 2 Diabetes. J Clin Endocrinol Metab. 2005 Aug;90(8):4888-94.

24. Bekiari E, Rizava C, Athanasiadou E, Papatheodorou K, Liakos A, Karagiannis T, et al. Systematic review and meta-analysis of vildagliptin for treatment of type 2 diabetes. 
Endocrine. 2016 Jun 29;52(3):458-80.

* Summary of clinical data on vildagliptin for type 2 diabetes mellitus.

25. Caires de Souza AL, Acurcio F de A, Guerra Júnior AA, Rezende Macedo do Nascimento RC, Godman B, Diniz LM. Insulin Glargine in a Brazilian State: Should the Government Disinvest? An Assessment Based on a Systematic Review. Appl Health Econ Health Policy. 2014 Feb 3;12(1):19-32.

26. Brasil. Banco de Preços em Saúde - BPS. Brasília: Ministério da Saúde; 2015.

27. Sonnenberg FA, Beck JR. Markov models in medical decision making: a practical guide. Med Decis Making. 1993;13(4):322-38.

28. Schweizer A, Couturier A, Foley JE, Dejager S. Comparison between vildagliptin and metformin to sustain reductions in $\mathrm{HbA} 1 \mathrm{c}$ over 1 year in drug-naïve patients with Type 2 diabetes. Diabet Med. 2007 Sep;24(9):955-61.

29. Bolli G, Dotta F, Colin L, Minic B, Goodman M. Comparison of vildagliptin and pioglitazone in patients with type 2 diabetes inadequately controlled with metformin. Diabetes, Obes Metab. 2009 Jun;11(6):589-95.

30. Ferrannini E, Fonseca V, Zinman B, Matthews D, Ahrén B, Byiers S, et al. Fifty-twoweek efficacy and safety of vildagliptin vs. glimepiride in patients with type 2 diabetes mellitus inadequately controlled on metformin monotherapy. Diabetes, Obes Metab. 2009 Feb;11(2):157-66.

31. Filozof C, Gautier J-F. A comparison of efficacy and safety of vildagliptin and gliclazide in combination with metformin in patients with Type 2 diabetes inadequately controlled with metformin alone: a 52-week, randomized study. Diabet Med. 2010 Mar;27(3):318-26.

32. Mathieu C, Barnett AH, Brath H, Conget I, de Castro JJ, Göke R, et al. Effectiveness and tolerability of second-line therapy with vildagliptin vs. other oral agents in type 2 diabetes: A real-life worldwide observational study (EDGE). Int J Clin Pract. 2013 Oct;67(10):947-56.

33. Montilla S, Marchesini G, Sammarco A, Trotta MP, Siviero PD, Tomino C, et al. Drug utilization, safety, and effectiveness of exenatide, sitagliptin, and vildagliptin for type 2 diabetes in the real world: Data from the Italian AIFA Anti-diabetics Monitoring Registry. Nutr Metab Cardiovasc Dis. 2014 Dec;24(12):1346-53. 
34. Brazil. SIHSUS - DATASUS [Internet]. SIHSUS - Sistema de Informações Hospitalares do SUS. 2016 [cited 2016 Jul 1]. Available from: http://datasus.saude.gov.br/sistemas-e-aplicativos/hospitalares/sihsus

35. Brazil. SIA - DATASUS [Internet]. SIA - Sistema de Informações Ambulatoriais do SUS. 2016 [cited 2016 Jul 1]. Available from: http://datasus.saude.gov.br/sistemas-eaplicativos/ambulatoriais/sia

36. Belo Horizonte. Transparência e acesso à informação - Remuneração - Servidores ativos [Internet]. 2016 [cited 2016 Jul 1]. Available from: http://portalpbh.pbh.gov.br/pbh/ecp/comunidade.do?evento=portlet\&pIdPlc=ecpTaxon omiaMenuPortal\&app=acessoinformacao\&tax $=41984 \&$ lang=pt_BR\&pg=10125\&taxp $=0 \&$

37. Berger ML, Bingefors K, Hedblom EC, Pashos CL, Torrance GW. Health Care Cost, Quality and Outcomes: ISPOR Book of Terms. 1st ed. Lawrenceville, NJ: ISPOR; 2003. 264 p.

38. The World Bank. PPP conversion factor, GDP (LCU per international \$) [Internet]. 2016 [cited 2016 Jul 15]. Available from: http://data.worldbank.org/indicator/PA.NUS.PPP

39. IBGE. IBGE | Brasil em síntese | contas nacionais | PIB - per capita [Internet]. PIB Per capita - Brasil - 2009/2015. 2016 [cited 2016 Jul 1]. Available from: http://brasilemsintese.ibge.gov.br/contas-nacionais/pib-per-capita

40. Briggs A, Sculpher M, Claxton K. Decision modelling for health economic evaluation. Oxford: Oxford University Press; 2006. 237 p.

41. Godman B, Gustafsson LL. A New Reimbursement System for Innovative Pharmaceuticals Combining Value-Based and Free Market Pricing. Appl Health Econ Health Policy. 2013 Feb 16;11(1):79-82.

42. Paris V, Belloni A. Value in Pharmaceutical Pricing. OECD Heal Work Pap. Paris; $2013 ; 63: 74$.

43. Godman B, Campbell S, Suh HS, Finlayson AE, Bennie M, Gustafsson LL. Ongoing measures to enhance prescribing efficiency across Europe: implications for other countries. J Heal Tech Assess. 2013;1:27-42.

44. Ford JA, Waugh N, Sharma P, Sculpher M, Walker A. NICE guidance: a comparative 
study of the introduction of the single technology appraisal process and comparison with guidance from Scottish Medicines Consortium. BMJ Open. 2012 Jan 30;2(1):e000671.

45. Svensson M, Nilsson FOL, Arnberg K. Reimbursement Decisions for Pharmaceuticals in Sweden: The Impact of Disease Severity and Cost Effectiveness. Pharmacoeconomics. 2015 Nov 21;33(11):1229-36.

46. Richter B, Bandeira-Echtler E, Bergerhoff K, Lerch C. Dipeptidyl peptidase-4 (DPP-4) inhibitors for type 2 diabetes mellitus. In: Richter B, editor. Cochrane Database of Systematic Reviews. Chichester, UK: John Wiley \& Sons, Ltd; 2008. p. CD006739.

47. Waugh N, Cummins E, Royle P, Clar C, Marien M, Richter B, et al. Newer agents for blood glucose control in type 2 diabetes: systematic review and economic evaluation. Health Technol Assess (Rockv). 2010 Jul;14(36):1-248.

* Detailed health technology assessment on DPP-4 inhibitors.

48. Hayes AJ, Leal J, Gray AM, Holman RR, Clarke PM. UKPDS Outcomes Model 2: a new version of a model to simulate lifetime health outcomes of patients with type 2 diabetes mellitus using data from the 30 year United Kingdom Prospective Diabetes Study: UKPDS 82. Diabetologia. 2013 Sep 22;56(9):1925-33.

49. Viriato D, Calado F, Gruenberger J-B, Ong SH, Carvalho D, Silva-Nunes J, et al. Costeffectiveness of metformin plus vildagliptin compared with metformin plus sulphonylurea for the treatment of patients with type 2 diabetes mellitus: a Portuguese healthcare system perspective. J Med Econ. 2014 Jul 23;17(7):499-507.

50. Nita ME, Eliaschewitz FG, Ribeiro E, Asano E, Barbosa E, Takemoto M, et al. Costeffectiveness and budget impact of saxagliptine as additional therapy to metformin for the treatment of diabetes mellitus type 2 in the Brazilian private health system. Rev Assoc Med Bras. 2012 May;58(3):294-301.

51. Geng J, Yu H, Mao Y, Zhang P, Chen Y. Cost Effectiveness of Dipeptidyl Peptidase-4 Inhibitors for Type 2 Diabetes. Pharmacoeconomics. 2015 Jun 4;33(6):581-97.

52. Baptista A, Teixeira I, Romano S, Carneiro AV, Perelman J. The place of DPP-4 inhibitors in the treatment algorithm of diabetes type 2: a systematic review of costeffectiveness studies. Eur J Heal Econ. 2016 Oct 17;[Epub ahead of print].

53. Charokopou M, McEwan P, Lister S, Callan L, Bergenheim K, Tolley K, et al. Cost- 
effectiveness of dapagliflozin versus DPP-4 inhibitors as an add-on to Metformin in the Treatment of Type 2 Diabetes Mellitus from a UK Healthcare System Perspective. BMC Health Serv Res. 2015 Jun 5;15(1):496.

54. Towards better patient care: drugs to avoid in 2016. Prescrire Int. 2016 Apr;25(170):105-11.

55. Ahuja V, Chou C-H. Novel Therapeutics for Diabetes: Uptake, Usage Trends, and Comparative Effectiveness. Curr Diab Rep. 2016 Jun 13;16(6):47. 